\title{
Identification of risk factors for treatment failure of closed reduction and abduction bracing after first-time total hip arthroplasty dislocation
}

\author{
Viktor Janz, Georgi I. Wassilew, Michael Putzier, Geraldine Kath, Carsten F. Perka
}

Department of Orthopaedic, Center for Musculoskeletal Surgery, Charité Universitätsmedizin Berlin, Germany

Submitted: 24 July 2017; Accepted: 13 June 2018

Online publication: 8 January 2021

Arch Med Sci 2022; 18 (1): 133-140

DOI: https://doi.org/10.5114/aoms/92214

Copyright (c) 2020 Termedia \& Banach

\section{Abstract}

Introduction: After a first-time total hip arthroplasty (THA) dislocation, a closed reduction followed by partial immobilization in an abduction brace is the recommended therapy. Despite modern abduction braces the success rate of conservative therapy is limited and evidence is scarce. The aim of this study was to identify risk factors for failure of conservative treatment after THA dislocation.

Material and methods: Eighty-seven patients, with conservative treatment of a first-time dislocation of a primary or revision THA, were included in this retrospective cohort study. Success was defined as a stable THA for a minimum of 6 months. Re-dislocation, open reduction or revision was defined as failure. The following risk factors were analyzed: gender, age, body mass index (BMI), ASA (American Society of Anesthesiologists) score, time of dislocation, head size, cup orientation, leg length, center of rotation and offset. Results: Sixty-seven percent of all patients experienced a re-dislocation, despite standardized conservative therapy. A BMI $\geq 25 \mathrm{~kg} / \mathrm{m}^{2}$, early THA dislocation, and low cup anteversion were associated with a statistically significantly higher risk for re-dislocation. None of the other risk-factors achieved statistical significance. A multifactorial risk-factor analysis was performed to assess whether a cup position outside of Lewinnek's safe zone in combination with gender, $\mathrm{BMI}$ and time to dislocation showed statistical significance for re-dislocation. Both $\mathrm{BMI} \geq 25 \mathrm{~kg} / \mathrm{m}^{2}$ and early dislocation showed a statistically higher failure rate. Cup position and gender were not significant.

Conclusions: $B M I \geq 25 \mathrm{~kg} / \mathrm{m}^{2}$, early THA dislocation and low cup anteversion were identified as significant risk factors for failure of conservative treatment with an abduction brace for first-time THA dislocation.

Key words: total hip arthroplasty dislocation, abduction brace, patientspecific risk factors.

\section{Introduction}

Dislocation is one of the most common complications after total hip arthroplasty (THA), with a reported incidence of $1-3 \%$, and is one of the leading reasons for revision [1-3]. The recommended treatment for first-time dislocation, after exclusion of a periprosthetic fracture, component malalignment or joint infection, is a closed reduction [4]. Following a successful reduction, an abduction brace is prescribed to limit hip flexion and prevent adduction. This restriction is continued for a min-

\author{
Corresponding author: \\ Viktor Janz \\ Orthopaedic Department \\ Center for Musculoskeletal \\ Surgery \\ Charité Universitätsmedizin \\ Berlin \\ Charitéplatz 1 \\ 10117 Berlin, Germany \\ E-mail: viktor.janz@charite.de
}


imum of 6 weeks by most surgeons $[5,6]$. However, the evidence for abduction braces is very scarce with only a few published studies available [4-7].

Total hip arthroplasty dislocation is a multi-factorial event and many patient-specific risk factors for THA dislocation, such as gender, body mass index (BMI), age, ASA (American Society of Anesthesiologists) score, time of dislocation and previous surgery, have been identified [1, 8-10]. In addition, multiple surgery-specific risk factors, such as surgical approach, head size, cup orientation, offset and leg length have also been documented [1, 11 , 12]. Despite this multitude of influencing factors, the recommended conservative treatment remains identical for all patients. Furthermore, it is currently unclear how cup position and the patient-specific risk factors influence the success of conservative treatment after first-time THA dislocation.

Historically, the most important radiological criterion for the assessment of THA stability has been Lewinnek's safe zone [12-16]. However, the efficacy of dislocation prevention of a cup positioned within Lewinnek's safe zone has been questioned in recent studies, since no significant correlation could be found between a cup position within Lewinnek's safe zone and the risk of THA dislocation $[2,17]$. Additionally to Lewinnek's safe zone, other factors influencing THA stability, such as the concept of combined anteversion, or spino-pelvic alignment, have been described [18-20].

It was the primary aim of this study to identify risk factors for failure of conservative treatment after first-time THA dislocation. The secondary aim was to investigate whether a cup position within Lewinnek's safe zone predicted successful conservative treatment after THA dislocation.

\section{Material and methods}

One hundred and twenty-seven patients who received conservative treatment for a first-time dislocation of a primary or revision THA at our department between 2007 and 2011 were identified by our institutional database and included in this retrospective cohort study. Prior to commencement the study was approved by our local ethics committee (Nr. EA1/045/16). All patients were referred to our tertiary care center for treatment of their primary THA dislocation.

Inclusion criteria were a primary dislocation of either a primary or revision THA, performed with an anterolateral or direct lateral approach, followed by standardized conservative treatment, consisting of an abduction brace, limiting hip flexion to $90^{\circ}$ and preventing adduction. The abduction brace was obligatory for $24 \mathrm{~h}$ /day for a total of 6 weeks. All patients obligatorily received an AP pelvic radiograph after reposition.

Exclusion criteria were open reposition $(n=2)$, THA revision surgery for any reason after dislocation $(n=23)$, non-THA components, or components with a reduced risk of dislocation, such as hemiarthroplasty, dual mobility cups or hip resurfacing $(n=15)$ or direct anterior or posterolateral surgical approaches. Deviation from the previously defined standardized conservative treatment, e.g. spica casts, was also excluded. After application of the exclusion criteria 87 patients, 33 primary THAs and 54 revision THAs, were included in the current study (Figure 1).

A radiological assessment and chart review were performed for each patient. Study endpoints were successful treatment defined as a stable THA, in the absence of recurrent dislocation, for a minimum duration of 6 months or treatment failure defined as re-dislocation, open reduction or other revision for any reason. The minimum follow-up was 6 months and the average follow-up in our cohort was 28 months (range: 6-58 months).

The following patient-specific risk factors were investigated, gender, age, BMI $\left(<25 \mathrm{~kg} / \mathrm{m}^{2}\right)$, ASA score, time of dislocation (cutoff between early and late dislocation, 90 days after surgery) and primary or revision surgery. The investigated surgery-specific risk factors included head size, cup inclination, cup anteversion, cup position in relation to Lewinnek's safe zone, as well as the cor-

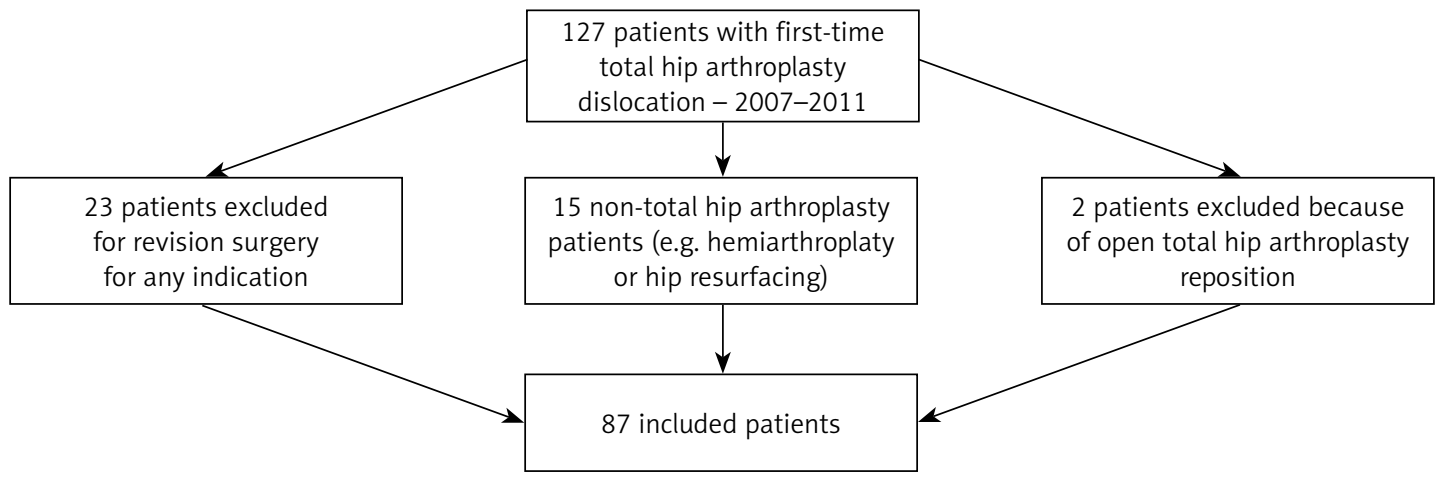

Figure 1. Flow chart showing the total number of patients identified with the inclusion criteria and the number of included patients after application of the exclusion criteria 
Table I. Demographic information, as well as the individual patient- and surgery-specific risk factors for the entire, primary-total hip arthroplasty (THA) and revision-THA cohorts

\begin{tabular}{|c|c|c|c|c|c|c|}
\hline \multirow[t]{2}{*}{ Parameter } & \multicolumn{2}{|c|}{ Entire cohort } & \multicolumn{2}{|c|}{ Primary THA } & \multicolumn{2}{|c|}{ Revision THA } \\
\hline & Mean & Range & Mean & Range & Mean & Range \\
\hline \multicolumn{7}{|l|}{ Patient-specific risk factors: } \\
\hline Age [years] & 69.0 & $36-98$ & 68.6 & $38-97$ & 69.3 & $36-98$ \\
\hline $\mathrm{BMI}\left[\mathrm{kg} / \mathrm{m}^{2}\right]$ & 26.6 & $17.1-478$ & 26.5 & $17.3-47.8$ & 26.7 & $17.0-41.3$ \\
\hline ASA score & 2.6 & $1-4$ & 2.5 & $2-3$ & 2.6 & $1-4$ \\
\hline Early dislocation [days] & 30.2 & $3-83$ & 19.3 & $3-59$ & 36.4 & $7-83$ \\
\hline Late dislocation [years] & 7.4 & $0.3-30.0$ & 7.7 & $3.0-20.0$ & 6.9 & $0.3-30.0$ \\
\hline \multicolumn{7}{|l|}{ Surgery-specific risk factors: } \\
\hline Cup inclination $\left[^{\circ}\right]$ & 46.6 & $12.3-73.3$ & 46.2 & $29.1-64.9$ & 47.0 & $12.3-73.3$ \\
\hline Cup anteversion $\left[^{\circ}\right]$ & 16.7 & $0.0-45.0$ & 18.2 & $2.6-39.6$ & 15.4 & $0.0-45.0$ \\
\hline \multirow[t]{5}{*}{ Head size $[\mathrm{mm}]$} & Size $(n)$ & Range & Size $(n)$ & Range & Size $(n)$ & Range \\
\hline & (1) & NA & (1) & NA & (0) & NA \\
\hline & (8) & NA & 28 & NA & (2) & NA \\
\hline & $(28)$ & NA & $(14)$ & NA & (14) & NA \\
\hline & $(7)$ & NA & 36 & NA & (5) & NA \\
\hline
\end{tabular}

rect reconstruction of leg length, center of rotation and offset. All patient-specific risk factors as well as the head size were acquired from the patient's charts. All of the other surgery-specific risk factors were calculated from the AP pelvic radiographs taken after closed reduction of the THA. A multi-factorial analysis of the radiological cup position, in reference to Lewinnek's safe zone, in combination with the patient-specific risk factors, BMI, gender and time of dislocation was also performed.

The demographics, as well as the patient- and surgery-specific risk factors, are displayed in Table I.

Cup anteversion and inclination were measured from AP pelvic radiographs according to the method first described by Bachhal et al. [21] (Figure 2). The AP pelvic radiographs were also used to measure hip offset, horizontal and vertical center of rotation as well as the leg length in a previously published manner [22, 23] (Figures 3-5). All radiological measurements were performed by one of the authors (G.K.) using digital templating software (TraumaCad, Brainlab AG, Munich Germany).

\section{Statistical analysis}

Statistical significance was defined as $p<0.05$ and calculated for all patient- and surgery-related risk factors using the $\chi^{2}$ and Mann-Whitney $U$ test.

\section{Results}

Sixty-seven percent of all patients $(n=58)$ experienced a re-dislocation in our cohort, despite a standardized conservative treatment.

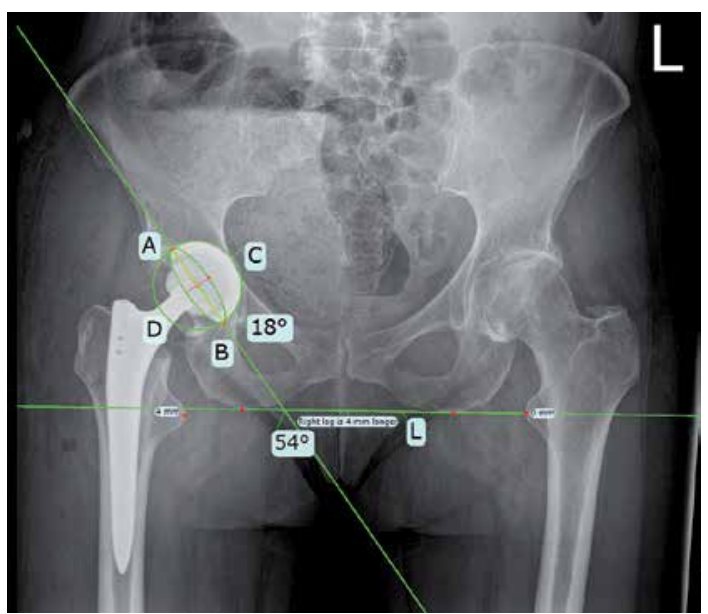

Figure 2. Radiological measurement of cup anteversion

The results for the statistical analysis of the patient- and surgery-specific risk factors are displayed in Table II. From the patient-specific risk factors BMI, time to dislocation, and cup anteversion showed statistical significance regarding the re-dislocation rate. In addition, the time to dislocation also showed statistical significance in a subgroup analysis of all primary THAs. None of the other patient- or surgery-specific risk factors analyzed achieved statistical significance.

It is worth noting that a high cup anteversion showed a positive effect regarding the success of conservative therapy. The average cup anteversion was $20^{\circ}$ for the group with successful therapy and $14^{\circ}$ for the group with re-dislocations. 


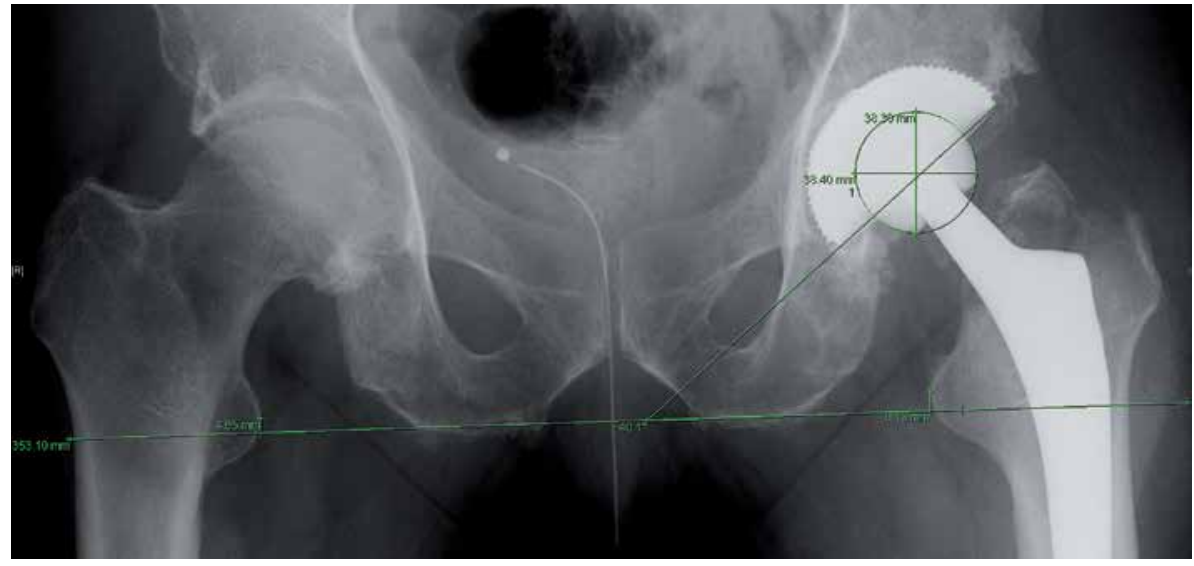

Figure 3. Radiological measurement of cup inclination and leg length

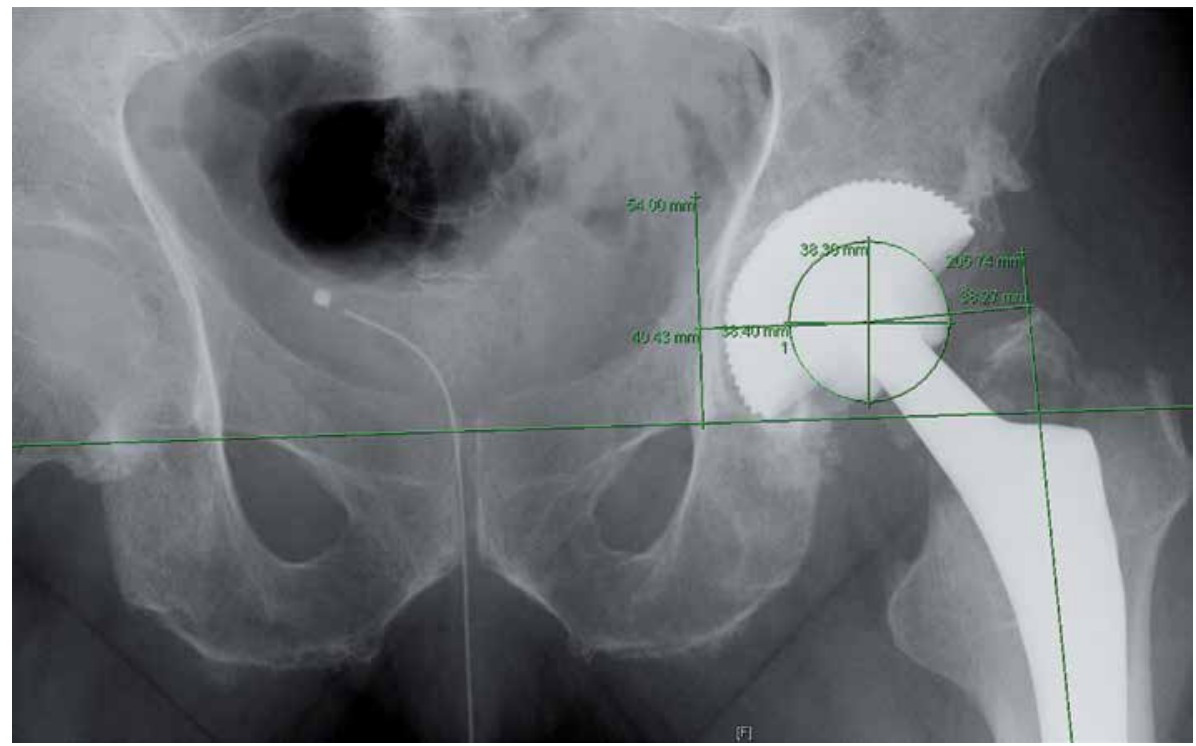

Figure 4. Radiological measurement of femoral and acetabular hip offset

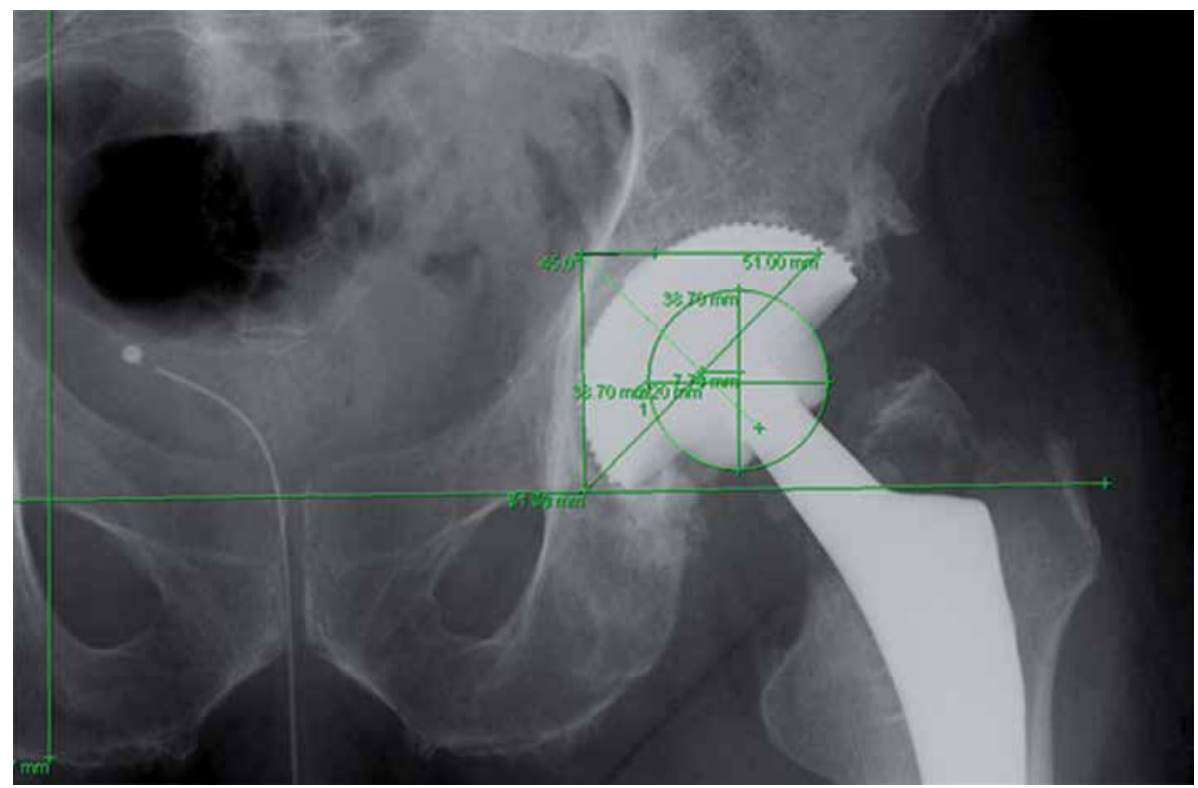

Figure 5. Radiological measurement of vertical and horizontal reconstruction of thecenter of rotation 
Table II. Results of the analysis of patient- and surgery-specific risk factors according to the success of conservative treatment (stable total hip arthroplasty (THA) or re-dislocation) after primary THA luxation for the entire patient, primary-THA and revision-THA cohorts

\begin{tabular}{|c|c|c|c|c|c|c|c|c|c|c|}
\hline \multirow{2}{*}{\multicolumn{2}{|c|}{ Parameter }} & \multicolumn{3}{|c|}{ Entire cohort } & \multicolumn{3}{|c|}{ Primary THA } & \multicolumn{3}{|c|}{ Revision THA } \\
\hline & & $\begin{array}{c}\text { Stable } \\
\text { THA }\end{array}$ & $\begin{array}{l}\text { Re-dislo- } \\
\text { cation }\end{array}$ & $P$-value & $\begin{array}{l}\text { Stable } \\
\text { THA }\end{array}$ & $\begin{array}{l}\text { Re-dislo- } \\
\text { cation }\end{array}$ & $P$-value & $\begin{array}{c}\text { Stable } \\
\text { THA }\end{array}$ & $\begin{array}{l}\text { Re-dislo- } \\
\text { cation }\end{array}$ & $P$-value \\
\hline \multicolumn{11}{|c|}{ Patient-specific risk factors: } \\
\hline \multicolumn{2}{|l|}{ Age [years] } & 71.0 & 71.0 & 0.80 & 74.0 & 67.5 & 0.49 & 71.0 & 72.0 & 0.70 \\
\hline \multicolumn{2}{|c|}{ Male; female } & $10 ; 19$ & $16 ; 42$ & 0.51 & $3 ; 9$ & $10 ; 16$ & 0.49 & $7 ; 10$ & $6 ; 26$ & 0.17 \\
\hline \multicolumn{2}{|c|}{$\mathrm{BMI}\left[\mathrm{kg} / \mathrm{m}^{2}\right]$} & 24.4 & 26.6 & 0.05 & 23.9 & 26.8 & 0.29 & 24.5 & 26.6 & 0.12 \\
\hline \multicolumn{2}{|l|}{$\begin{array}{l}\text { ASA }<3 \\
A S A \geq 3\end{array}$} & $\begin{array}{l}15 \\
13\end{array}$ & $\begin{array}{c}20 \\
36\end{array}$ & 0.29 & $\begin{array}{l}4 ; \\
7\end{array}$ & $\begin{array}{c}16 \\
10\end{array}$ & 0.13 & $\begin{array}{l}9 \\
8\end{array}$ & $\begin{array}{c}20 \\
10\end{array}$ & 0.37 \\
\hline \multicolumn{2}{|c|}{$\begin{array}{l}\text { Early dislocation } \\
\text { [days] }\end{array}$} & 37.0 & 17.5 & 0.02 & 25.0 & 13.5 & 0.05 & 50.0 & 23.0 & 0.31 \\
\hline \multicolumn{2}{|c|}{$\begin{array}{l}\text { Late dislocation } \\
\text { [years] }\end{array}$} & 8.0 & 4.0 & 0.10 & 8.0 & 6.0 & 0.72 & 30.0 & 1.5 & 0.25 \\
\hline \multicolumn{11}{|c|}{ Surgery-specific risk factors: } \\
\hline \multicolumn{2}{|c|}{ Leg length $[\mathrm{mm}]$} & 2.0 & -0.5 & 0.83 & -2.0 & -1.6 & 0.82 & 3.1 & 3.5 & 1.00 \\
\hline \multicolumn{2}{|c|}{$\begin{array}{l}\text { Cup inclination } \\
{\left[^{\circ}\right]}\end{array}$} & 46.5 & 47.4 & 0.66 & 43.2 & 47.5 & 0.10 & 47.5 & 47.4 & 0.45 \\
\hline \multicolumn{2}{|c|}{$\begin{array}{l}\text { Cup anteversion } \\
{\left[{ }^{\circ}\right]}\end{array}$} & 20.3 & 13.9 & 0.03 & 22.1 & 15.7 & 0.07 & 15.4 & 13.1 & 0.19 \\
\hline \multirow{2}{*}{\multicolumn{2}{|c|}{ Offset [mm] }} & 65.0 & 63.2 & 0.60 & 66.0 & 61.5 & 0.12 & 62.2 & 63.5 & 0.46 \\
\hline & & $n$ & $n$ & $P$-value & $n$ & $n$ & $P$-value & $n$ & $n$ & $P$-value \\
\hline \multirow{4}{*}{$\begin{array}{l}\text { Head size } \\
{[\mathrm{mm}]}\end{array}$} & 22 & 0 & 1 & 0.91 & 0 & 1 & 0.68 & 0 & 0 & 0.42 \\
\hline & 28 & 14 & 7 & & 1 & 5 & & 3 & 2 & \\
\hline & 32 & 11 & 23 & & 5 & 9 & & 6 & 14 & \\
\hline & 36 & 3 & 6 & & 5 & 1 & & 2 & 5 & \\
\hline
\end{tabular}

In addition to the surgery-specific risk factors displayed in Table II, the correct reconstruction of the center of rotation, leg length and offset were analyzed. None of these factors achieved statistical significance in our patient cohort. Additionally, the number of previous revision procedures performed did not show statistical significance regarding the rate of re-dislocation within the revision THA patient cohort.

To better visualize the influence of cup positioning in regard to Lewinnek's safe zone, the values for cup anteversion and inclination are displayed in Figure 6.

Since the outliers outside of Lewinnek's safe zone are the patients at high risk for recurrent dislocation, the absolute numbers of outliers for the group with successful and failed conservative therapy were compared for statistical significance. In the patient group with treatment failure, 59\% (27 of 46) of all patients represented outliers outside of Lewinnek's safe zone. In the patient group with successful conservative treatment, 58\% (14 of 24) of patients were outliers regarding cup positioning. This difference in the number of out- liers between groups was not statistically significant $(p=0.98)$.

The multi-factorial analysis of BMI and cup position, within Lewinnek's safe zone, showed sta-

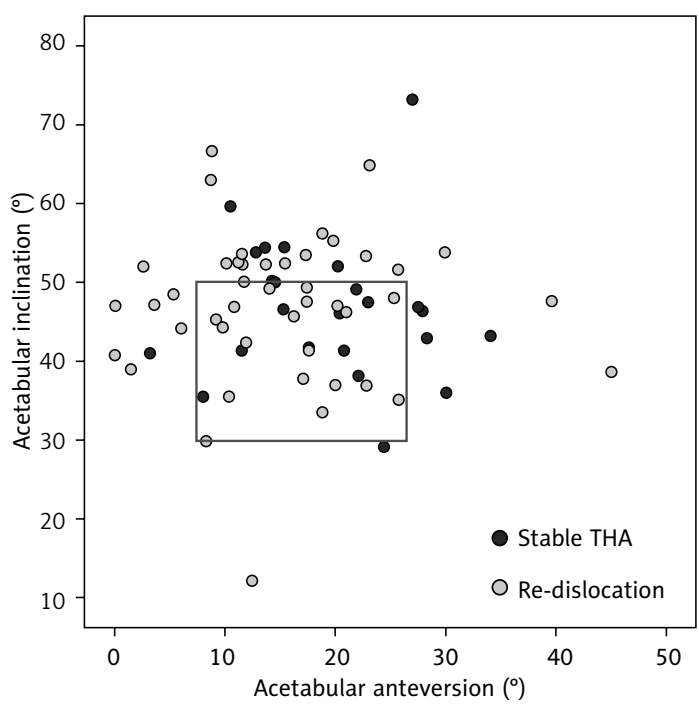

Figure 6. Scatter plot for cup inclination and anteversion of the patients with successful conservative treatment and re-dislocation 
tistical significance. From all patients with a cup position outside of Lewinnek's safe zone, there was a significantly higher failure rate $(p=0.03)$ of the conservative treatment in overweight patients $\left(\mathrm{BMI} \geq 25 \mathrm{~kg} / \mathrm{m}^{2}\right)(n=19)$ than in non-overweight patients $\left(\mathrm{BMI}<25 \mathrm{~kg} / \mathrm{m}^{2}\right)(n=8)$. Additionally, the multi-factorial analysis of time to dislocation and cup position also showed statistical significance. From all patients with a cup position outside of Lewinnek's safe zone, there was a significantly higher failure rate $(p=0.03)$ of the conservative treatment in patients with an early dislocation ( $\leq 40$ days) $(n=11)$ than in patients with a late dislocation ( $>40$ days) $(n=17)$. The multi-factorial analysis of cup position and gender did not show statistical significance $(p=0.49)$.

\section{Discussion}

To our knowledge, this is the first study to investigate the risk factors for failure of conservative treatment, using an abduction brace, after firsttime THA dislocation. Despite the lack of evidence regarding treatment efficacy, and high re-dislocation rates, a closed reduction followed by partial immobilization in an abduction brace for 6 weeks remains a cornerstone of conservative therapy $[5,6,24]$. Dewal et al. reported a re-dislocation rate of $61 \%$, despite the use of an abduction brace, and could not show a significant reduction in the re-dislocation rate through the use of an abduction brace in either first-time THA dislocation or cases of recurrent dislocation [5]. This high rate of recurrent dislocation is in agreement with the results of our current study [5].

A second factor influencing the success of conservative treatment with an abduction brace is the duration of brace wear. The traditional duration of brace wear is 6 weeks, although some authors recommend an extended duration of 12 weeks [6, 25]. However, neither Brennan et al., with a brace duration of 6 weeks, nor Murray et al., with a brace duration of 12 weeks, found a statistically significant benefit of abduction bracing in regard to avoiding THA re-dislocation $[6,25]$.

One of the clinically most important factors for evaluation of THA stability is a cup position within Lewinnek's safe zone [12]. However, recent studies have questioned the efficacy of dislocation prevention through a cup position within Lewinnek's safe zone $[2,17]$. While these data should not be interpreted that a cup position outside of Lewinnek's safe zone does not represent a risk factor for dislocation, the studies do allow the conclusion that a cup positioned within Lewinnek's safe zone does not guarantee THA stability. Abdel et al. demonstrated that a cup positioning within Lewinnek's safe zone is not a predictor for avoid- ing dislocation, when a posterolateral approach is used [17]. In a subgroup analysis of patients with an anterolateral approach, the authors found patients with a cup anteversion of $\leq 10^{\circ}$ to have a higher incidence of dislocation. They postulated that defining a new "safe zone" with more anteversion for the anterolateral approach might aid in preventing dislocation. As shown in Figure 5, the simple hypothesis of defining a new "safe zone" based on cup position alone cannot be supported by our results, as there was no difference in the number of outliers or cup position between the two patient groups in our current study. This is in line with the results of Esposito et al., who could not find a "safe zone" for cup positioning in regard to THA dislocation [2]. However, there was a trend toward fewer dislocations in the zone of $48 \pm 10^{\circ}$ inclination and $24 \pm 10^{\circ}$ anteversion, suggesting that a higher value for cup anteversion than the traditional value $15 \pm 10^{\circ}$ of anteversion suggested by Lewinnek can be protective in regard to THA dislocation $[2,12]$. Our results confirm this trend, as we found that a higher value for cup anteversion is a statistically significant factor in predicting successful conservative treatment after first time THA dislocation.

The fact that the traditional values of cup anteversion introduced by Lewinnek et al. might be underestimated is also supported by the CTbased investigation of 336 native acetabula by Tohtz et al. [26]. The average values for acetabular anteversion were $25^{\circ}$ for female hips and $21^{\circ}$ for male hips [26]. Both of these values show that a higher target value for cup anteversion, than the traditional $15^{\circ}$ suggested by Lewinnek, would represent an acetabular reconstruction closer to the anatomical norm. Currently, the recommendations for a "safe zone" in cup positioning are independent of the utilized approach. A more differentiated consideration of cup positioning, dependent on the utilized approach, might lead to a further improvement in reducing the rate of THA dislocation.

The following risk factors were identified as significant for the failure of conservative treatment in the current study: an early dislocation, $\mathrm{BMI}<25$ $\mathrm{kg} / \mathrm{m}^{2}$ and a low cup anteversion. An early dislocation, within the first 6 postoperative weeks, also represents a known risk factor for recurrent dislocations $[27,28]$. In the early postoperative phase, there is insufficient scar formation and consolidation of the soft tissues, both of which decrease joint stability. This is especially significant when a minimally invasive anterolateral approach is used, as was the case in our cohort, since a complete capsular resection is often performed in this approach to facilitate femoral exposure [29, 30]. This factor might not be as important in cas- 
es with a posterior approach, since it has been shown that a capsular repair decreases the incidence of THA dislocation [31, 32]. The overall lower dislocation rate after primary THA utilizing an anterolateral approach, in direct comparison to the posterior approach, might also explain why no statistical significance was achieved when comparing the different head sizes within our patient collective.

It is well documented that overweight patients are at a higher risk for THA dislocation, because of extraarticular fatty tissue acting as a fulcrum and increasing the risk of soft tissue impingement $[33,34]$. The mechanisms that lead to this increased risk of THA dislocation are the same as those that lead to recurrent dislocation, despite the use of an abduction brace. While an abduction brace can limit an active adduction of the leg, it cannot prevent the lateralization moment of the proximal femur induced by the soft tissue of the thighs [9]. This study is the first to show that a BMI $>25 \mathrm{~kg} / \mathrm{m}^{2}$ is also a significant factor for failure of conservative treatment after THA dislocation.

The limitations of our current study are mostly due to the retrospective study design and the low incidence of dislocation after primary THA, performed through a lateral or anterolateral approach, which resulted in a long inclusion period to acquire a sufficient patient collective. Since this study was performed at a tertiary referral hospital, a significant percentage of patients had their surgical procedures performed at other hospitals. This led to a large number of surgeons and a very heterogeneous patient collective, albeit one that is very representative of the clinical routine. Additionally, patients treated with a posterior approach were not represented in this study. Also, due to the retrospective nature of our study it was not possible to assess the direction of THA dislocation, so an analysis of the mechanism of dislocation and the direction of dislocation could not be performed. CT data were also not available from all patients included in the study, so an assessment of the combined anteversion of the THAs was not possible.

Our results suggest that the success rate of conservative treatment might improve if future patients are preselected prior to initiation of conservative therapy. Appropriate selection criteria for patients with a high risk of failure of conservative treatment are cup outliers outside of Lewinnek's safe zone, patients with an increased BMI and early dislocation. Future prospective studies should be performed to investigate whether patient selection actually results in an increased success rate of conservative therapy. Additionally, the results of this study can help to better educate pa- tients about their individual risk factors regarding the failure of conservative treatment as well as the overall success rate of conservative treatment after first-time THA dislocation. This can help to improve the patient's acceptance and compliance regarding wearing the abduction brace, as well as to curb exaggerated expectations regarding the success rate of conservative treatment.

Proper patient selection, with the risk factors identified in this study, close patient guidance and a detailed diagnostic algorithm to identify the cause of THA instability remain essential for successful conservative treatment as the management of THA instability remains a challenge.

\section{Acknowledgments}

We would like to thank Franek Haschke, MD, for his organizational assistance and support in data collection.

\section{Conflict of interest}

The authors declare no conflict of interest.

\section{References}

1. Khatod M, Barber T, Paxton E, Namba R, Fithian D. An analysis of the risk of hip dislocation with a contemporary total joint registry. Clin Orthop Relat Res 2006; 447: 19-23.

2. Esposito $\mathrm{Cl}$, Gladnick BP, Lee YY, et al. Cup position alone does not predict risk of dislocation after hip arthroplasty. J Arthroplasty 2015; 30: 109-13.

3. Sadoghi P, Liebensteiner M, Agreiter M, Leithner A, Bohler N, Labek G. Revision surgery after total joint arthroplasty: a complication-based analysis using worldwide arthroplasty registers. J Arthroplasty 2013; 28: 1329-32.

4. Patel PD, Potts A, Froimson MI. The dislocating hip arthroplasty: prevention and treatment. J Arthroplasty 2007; 22 (4 Suppl 1): 86-90.

5. Dewal H, Maurer SL, Tsai P, Su E, Hiebert R, Di Cesare PE. Efficacy of abduction bracing in the management of total hip arthroplasty dislocation. J Arthroplasty 2004; 19: 733-8.

6. Murray TG, Wetters NG, Moric M, Sporer SM, Paprosky WG, Della Valle CJ. The use of abduction bracing for the prevention of early postoperative dislocation after revision total hip arthroplasty. J Arthroplasty 2012; 27 (8 Suppl): 126-9.

7. Clayton ML, Thirupathi RG. Dislocation following total hip arthroplasty. Management by special brace in selected patients. Clin Orthop Relat Res 1983; 177: 154-9.

8. Jolles BM, Zangger P, Leyvraz PF. Factors predisposing to dislocation after primary total hip arthroplasty: a multivariate analysis. J Arthroplasty 2002; 17: 282-8.

9. Elkins JM, Daniel M, Pedersen DR, et al. Morbid obesity may increase dislocation in total hip patients: a biomechanical analysis. Clin Orthop Relat Res 2013; 471:971-80.

10. Berry DJ, von Knoch $M$, Schleck CD, Harmsen WS. The cumulative long-term risk of dislocation after primary Charnley total hip arthroplasty. J Bone Joint Surg Am 2004; 86-a: 9-14. 
11. Sheth D, Cafri G, Inacio MC, Paxton EW, Namba RS Anterior and anterolateral approaches for THA are associated with lower dislocation risk without higher revision risk. Clin Orthop Relat Res 2015; 473: 3401-8.

12. Lewinnek GE, Lewis JL, Tarr R, Compere CL, Zimmerman JR. Dislocations after total hip-replacement arthroplasties. J Bone Joint Surg Am 1978; 60: 217-20.

13. Seagrave KG, Troelsen A, Malchau H, Husted H, Gromov K. Acetabular cup position and risk of dislocation in primary total hip arthroplasty. Acta Orthop 2017; 88: 10-7.

14. Grammatopoulos G, Thomas GE, Pandit H, Beard DJ, Gill HS, Murray DW. The effect of orientation of the acetabular component on outcome following total hip arthroplasty with small diameter hard-on-soft bearings. Bone Joint J 2015; 97-b: 164-72.

15. Danoff JR, Bobman JT, Cunn G, et al. Redefining the acetabular component safe zone for posterior approach total hip arthroplasty. J Arthroplasty 2016; 31: 506-11.

16. Opperer M, Lee YY, Nally F, Blanes Perez A, GoudarzMehdikhani K, Gonzalez Della Valle A. A critical analysis of radiographic factors in patients who develop dislocation after elective primary total hip arthroplasty. Int Orthop 2016; 40: 703-8.

17. Abdel MP, von Roth P, Jennings MT, Hanssen AD, Pagnano MW. What safe zone? The vast majority of dislocated THAs are within the lewinnek safe zone for acetabular component position. Clin Orthop Relat Res 2016; 474: 386-91.

18. Amuwa C, Dorr LD. The combined anteversion technique for acetabular component anteversion. J Arthroplasty 2008; 23: 1068-70

19. Lum ZC, Coury JG, Cohen JL, Dorr LD. The current knowledge on spinopelvic mobility. J Arthroplasty 2018; 33: 291-6.

20. Sultan AA, Khlopas A, Piuzzi NS, Chughtai M, Sodhi N, Mont MA. The impact of spino-pelvic alignment on total hip arthroplasty outcomes: a critical analysis of current evidence. J Arthroplasty 2018; 33: 1606-16.

21. Bachhal V, Jindal N, Saini G, et al. A new method of measuring acetabular cup anteversion on simulated radiographs. Int Orthop 2012; 36: 1813-8.

22. Pluot E, Davis ET, Revell M, Davies AM, James SL. Hip arthroplasty. Part 2: normal and abnormal radiographic findings. Clin Radiol 2009; 64: 961-71.

23. Mulcahy H, Chew FS. Current concepts of hip arthroplasty for radiologists: part 1, features and radiographic assessment. AJR Am J Roentgenol 2012; 199: 559-69.

24. Dorr LD, Wolf AW, Chandler R, Conaty JP. Classification and treatment of dislocations of total hip arthroplasty. Clin Orthop Relat Res 1983; 173: 151-8.

25. Brennan SA, Khan F, Kiernan C, et al. Dislocation of primary total hip arthroplasty and the risk of redislocation. Hip Int 2012; 22: 500-4.

26. Tohtz SW, Sassy D, Matziolis G, Preininger B, Perka C, Hasart O. CT evaluation of native acetabular orientation and localization: sex-specific data comparison on 336 hip joints. Technol Health Care 2010; 18: 129-36.

27. Leichtle UG, Leichtle Cl, Taslaci F, Reize P, Wunschel M. Dislocation after total hip arthroplasty: risk factors and treatment options. Acta Orthop Traumatol Turc 2013; 47: 96-103.

28. Joshi A, Lee CM, Markovic L, Vlatis G, Murphy JC. Prognosis of dislocation after total hip arthroplasty. J Arthroplasty 1998; 13: 17-21.

29. Prietzel T, Hammer N, Schleifenbaum S, et al. The impact of capsular repair on the dislocation rate after primary total hip arthroplasty: a retrospective analysis of 1972 cases. Z Orthop Unfall 2014; 152: 130-43.

30. Rottinger $\mathrm{H}$. The MIS anterolateral approach for THA. Orthopade 2006; 35: 708, 710-5.

31. Suh KT, Park BG, Choi YJ. A posterior approach to primary total hip arthroplasty with soft tissue repair. Clin Orthop Relat Res 2004; 418: 162-7.

32. Tsai SJ, Wang CT, Jiang CC. The effect of posterior capsule repair upon post-operative hip dislocation following primary total hip arthroplasty. BMC Musculoskelet Disord 2008; 9: 29.

33. Hernigou P, Trousselier M, Roubineau F, Bouthors C, Flouzat Lachaniette $\mathrm{CH}$. Dual-mobility or constrained liners are more effective than preoperative bariatric surgery in prevention of THA dislocation. Clin Orthop Relat Res 2016; 474: 2202-10.

34. Davis AM, Wood AM, Keenan AC, Brenkel IJ, Ballantyne JA. Does body mass index affect clinical outcome post-operatively and at five years after primary unilateral total hip replacement performed for osteoarthritis? A multivariate analysis of prospective data. J Bone Joint Surg Br 2011; 93: 1178-82. 